Res Publica. Revista de Historia de las Ideas Políticas

ISSN: $1576-4184$

\title{
La organización constitucional argentina y el '48 europeo: el caso de Mariano Fragueiro
}

\author{
Tomás Wieczorek*
}

Recibido: 13 de agosto de 2018 / Aceptado: 1 de noviembre de 2018

Resumen. La historia intelectual de la organización constitucional argentina está signada por una serie de rupturas y discontinuidades respecto a lo político y sus referencias teóricas. Si en la segunda mitad del siglo XIX predominó la tesis de la falta de "originalidad" de la Constitución de 1853, en los albores del siglo XX se trastocaría radicalmente el signo interpretativo, para celebrar la originalidad de la obra alberdiana. Sería la escuela revisionista -o militante- la que, hacia mediados del siglo pasado, volvería sobre el carácter del pensamiento constitucional argentino, para advertir que sus principales referencias teórico-políticas se incardinan en el horizonte del revolucionario 1848 europeo. El presente trabajo se dirige a restituir los modos de apropiación y distanciamiento a este respecto de un "olvidado" de la organización nacional argentina: Mariano Fragueiro, autoproclamado socialista y primer Ministro de Hacienda constitucional de la Confederación Argentina.

Palabras clave: Argentina; Constitución; Socialismo; Fragueiro.

\section{[en] The Constitutional Organization in Argentina and the European 1848: the Case of Mariano Fragueiro}

Abstract. The intellectual history of the Argentine constitutional organization is marked by a series of ruptures and discontinuities regarding the political and its theoretical references. If in the second half of the nineteenth century the "the lack of originality" of the 1853 constitution thesis prevailed, at the dawn of the 20th century, the interpretive sign would be radically disrupted, in order to celebrate the originality of the Alberdian work. Towards the middle of the last century, it would be the revisionist -or militant- historiographical school the one that would warn that the main theoretical-political references of Argentine constitutional thought, are incardinated in the horizon of the European 1848 revolution. The present paper aims to restore the modes of appropriation and distancing in this regard of Mariano Fragueiro, self-proclaimed socialist and first constitutional finance minister of the Argentine Confederation.

Keywords: Argentina; Constitution; Socialism; Fragueiro.

Sumario: 1. Introducción. 2. Liberalismo y socialismo en la formación del momento constituyente. 3. Fragueiro, el 48 europeo y su plan constitucional. 4. Conclusión: Fragueiro, su derrota y su prognosis.

Cómo citar: Wieczorek, T. (2018). La organización constitucional argentina y el '48 europeo: el caso de Mariano Fragueiro, en Res publica 21.3, 633-649.

\footnotetext{
* Universidad de Buenos Aires. Facultad de Ciencias Sociales. Instituto de Investigaciones Gino Germani. Buenos Aires, Argentina / CONICET, Buenos Aires, Argentina.

tomaswiecz@gmail.com
} 


\section{Introducción}

En el año 1852 las tropas rosistas son derrotadas por el Ejército Grande Aliado de Sud-América, capitaneado por el hasta entonces gobernador de la Provincia de Entre Ríos Justo José de Urquiza. Se abría entonces un proceso político que, por primera vez, daría con un texto constitucional eficaz para la República Argentina: la célebre constitución de 1853 se convertiría desde entonces en uno de los significantes privilegiados de la disputa política argentina. Hacia atrás, se vislumbran cincuenta años signados por la disolución de la unidad colonial en soberanías provinciales, que alcanza su cenit a mediados de 1820 , y su posterior y progresiva reunificación ${ }^{1}$. Hacia adelante, se desenvuelve el canónicamente denominado "proceso de organización nacional", definido por la formación del aparato estatal nacional consolidado hacia la década de 1880 .

La Provincia de Buenos Aires, sin embargo, no respondería a la convocatoria del Congreso General Constituyente de la Confederación Argentina, para lanzarse a una política secesionista que se consagraría con la sanción de la constitución del Estado de Buenos Aires: desde entonces tendría lugar lo que Oscar Oszlak denominara el "duopolio" de la representación exterior ${ }^{2}$, sentándose las bases de un enfrentamiento que se prolongaría hasta fines de 1861, y que encontraría en el abierto conflicto militar la expresión esporádica de una permanente guerra económica ${ }^{3}$. A partir de esta clave, buena parte de las lecturas del momento constitucional de 1852-1853 han tendido a contraponer las posiciones de Juan Bautista Alberdi, alineado con la Confederación urquicista, y Domingo Faustino Sarmiento, ligado al bando bonaerense ${ }^{4}$. Desde el

J. C. Chiaramonte, "El federalismo argentino en la primera mitad del siglo XIX", en M. Carmagnani (coord.), Federalismos latinoamericanos. México, Brasil, Argentina, México D.F., El Colegio de México-Fondo de Cultura Económica, 1993, pp. 81-132; J. C. Chiaramonte, Ciudades, provincias, estados: Orígenes de la Nación Argentina (1800-1846), Buenos Aires, Emecé Editores, 2006; y N. Goldman, "Los orígenes del federalismo rioplatense (1820-1831)", en N. Goldman (dir.), Nueva Historia Argentina. Tomo 3. Revolución, República, Confederación (1806-1852), Buenos Aires, Sudamericana, 1998, pp. 103-124.

2 O. Oszlak, "Formación histórica del estado argentino: La conquista del orden". I Seminario Latino-Americano de Politicas Públicas, FUNDAP/CLACSO, Sao Paulo, noviembre de 1979, disponible en: http://www.oscaroszlak.org.ar/images/articulos-espanol/La\%20 conquista\%20del\%20orden.pdf

3 J. Álvarez, "La guerra económica entre la Confederación Argentina y Buenos Aires", en R. Levene (dir.), Historia de la Nación Argentina, Vol. VIII. Buenos Aires, Academia Nacional de Historia, 1946; J. R. Scobie, La lucha por la consolidación de la nacionalidad argentina, 1852-1862, Buenos Aires, Hachette, 1964; J. C. Garavaglia, La disputa por la construcción nacional argentina. Buenos Aires, la Confederación y las provincias (1850-1865), Buenos Aires, Prometeo, 2015.

4 Dos conjuntos de razones explican la centralidad de esta polémica en la historia intelectual y conceptual de la constitución y el constitucionalismo argentino. En primer lugar, por motivos "generacionales": ambos integran el colectivo romántico argentino -el de la Generación del 1837 y la Asociación de la Joven Argentina-: Lo que primeramente fuera un círculo juvenil dispuesto a relevar a la generación precedente en el manejo de la cosa pública -para lo cual hicieran claros esfuerzos de acercamiento al gobierno de Rosas-, se había lanzado luego de la emigración a la política revolucionaria -que incluiría la coalición con potencias extranjeras como Inglaterra y Francia- contra las autoridades de la Confederación. Luego de las derrotas que sufriera esta la política de manos de Rosas en los años 1838-1840 y 1846-47, los políticos románticos mostraron una nueva disposición a pactar con las élites -especialmente económicas- forjadas al calor del férreo sistema rosista. En este sentido, no se debe desdeñar la importancia de este colectivo como seminal para la historiografía argentina y, más ampliamente, para toda la vida política nacional de la segunda mitad del siglo XIX. En segundo lugar, ambos trabaron una estrecha relación durante su emigración en Chile, que se rompería a partir de sus diferentes posicionamientos de cara a la derrota de Rosas y el proceso constituyente motorizado por Urquiza. Así, mientras ambos celebran el triunfo urquicista, luego de un intento de aproximación al triunfador de Caseros, Sarmiento se considera desairado por éste, y con su Campaña en el Ejército grande se lanza al ataque de quien hasta hace poco celebrara como un libertador. Esto iniciaría una polémica pública con Alberdi, quien se mantendría fiel a la política de la Confederación Argentina capitaneada por Urquiza: la dura disputa epistolar entre ambos se plasmaría en las 
punto de vista jurídico, en esta polémica se habría figurado la antinomia fundamental del constitucionalismo argentino: aquella en torno al carácter del régimen federal argentino en relación al modelo estadounidense ${ }^{5}$. En línea con la posición de Sarmiento, desde el denominado "Proceso de Organización Nacional" (1862-1880) las corrientes de ideas dominantes habían tendido, en un doble movimiento, tanto a desdibujar los rasgos originales del dispositivo constitucional de 1853 como, en caso de reconocer estas peculiaridades, tratarlas como errores de tipo doctrinario, es decir, desviaciones respecto a la "recta" doctrina constitucional federal estadounidense.

Entre fines del siglo XIX y principios del XX se produce por primera vez el destaque de la originalidad o argentinidad de la Constitución, impulsada por la combinación de una fuerte transformación científica e institucional de la cultura jurídica argentina y una cierta rehabilitación de la figura de Alberdi por parte de Bartolomé Mitre $^{6}$. Rodolfo Rivarola, Juan Álvarez y Nicolás Matienzo publicaron en este período obras de envergadura que fueron decisivas en para revolucionar las interpretaciones históricas del momento constituyente de 1853 y del ciclo constitucional por él inaugurado ${ }^{7}$ : elogiosas o condenatorias, estas visiones renovadoras tendieron a cen-

Cartas quillotanas de Alberdi y las Ciento y una del sanjuanino. Cf.: T. Halperín Donghi, "Una nación para el desierto argentino", en T. Halperín Donghi (comp.), Proyecto y construcción de una nación (Argentina 18461880), Buenos Aires, Espasa Calpa-Ariel, 1995, pp. 7-107.

5 Alberdi había afirmado en sus Bases que el error de los federales argentinos en el último Congreso Constituyente argentino (1824-1826) era haber defendido el sistema confederal según los Artículos de 1778, y no el sistema federal según la Constitución de 1787, argumento retomado por los constituyentes de 1853 al indicar que el proyecto de constitución estaba vaciado en el molde de la estadounidense, "único modelo de verdadera federación que existe en el mundo". (Emilio Ravignani (comp.), Asambleas Constituyentes Argentinas: seguidas de los textos constitucionales, legislativos y pactos interprovinciales que organizaron políticamente la Nación, Tomo IV, Buenos Aires, Talleres de Jacobo Peuser, 1937, pp. 468 y 479). Siguiendo esta línea, en sus Comentarios a la constitución... Sarmiento enumera los "errores" de la Constitución argentina, que no son otros que aquellos puntos en los que se separa del sistema federal de 1787. La "solución" propuesta consiste no sólo en una reforma constitucional, sino -más significativamente- en la incorporación inmediata de la jurisprudencia suprema estadounidense. La réplica alberdiana en sus Estudios... enfatiza una y otra vez en la originalidad de la obra constitucional argentina, destacando en especial que se trata de un régimen más centralizado (en términos verticales) y concentrado (en términos horizontales). (Juan Bautista Alberdi, Bases y puntos de partida para la organización política de la República Arjentina, derivados de la ley que preside el desarrollo de la civilización en la América del Sud, y del tratado litoral del 4 de enero de 1831. Segunda edición, correjida, aumentada de muchos parágrafos y de un proyecto de constitución concebido según las bases propuestas, Valparaíso, Imprenta del Mercurio, 1852; Domingo Faustino Sarmiento, Comentarios de la Constitución de la Confederacion Arjentina: con numerosos documentos illustrativos del texto, Santiago, Belin, 1853; Juan Bautista Alberdi, Estudios sobre la Constitución Arjentina de 1853, en que se restablece su mente alterada por comentarios hostiles, y se designan los antecedentes nacionales que han sido bases de su formación y deben serlo de su jurisprudencia, Valparaíso, Imprenta del Diario, 1853).

6 E. J. Palti, El pensamiento de Alberdi, Tesis de Licenciatura, Facultad de Filosofía y Letras-Universidad de Buenos Aires, 1989, pp. 5-6; M. R. Polotto, "La argentinidad de la Constitución. Nuevos enfoques para el estudio de nuestra carta magna a principios del siglo XX (1901-1930)", en Revista Historia del Derecho, No 37, 2009, pp. 1-11, disponible en: http://www.scielo.org.ar/pdf/rhd/n37/n37a04.pdf.

Para una visión de conjunto sobre el período: Natalio Botana, Pensamiento y proyectos políticos 1880-1916, en Academia Nacional de Historia, La Nueva Historia de la Nación. Tomo V, Buenos Aires, Planeta, 2000, pp. $47-$ 75; O. Terán, Vida intelectual en el Buenos Aires fin-de-siglo (1880-1910). Derivas de la "cultura cientifica", Buenos Aires, Fondo de Cultura Económica, 2000; C. Altamirano, "Entre el naturalismo y la psicología. El comienzo de la ciencia social en Argentina”, en F. Neiburg y M. Plotkin (eds.), Intelectuales y Expertos, Buenos Aires, Paidos, 2004, pp. 31- 65.

$7 \quad$ R. Rivarola, Del régimen federativo al unitario. Estudio sobre la organización política de la Argentina, Buenos Aires, J. Peuser, 1908; J. N. Matienzo, El gobierno representativo federal en la República Argentina. Buenos Aires, Coni hermanos, 1910; J. Álvarez, Las guerras civiles argentinas y el problema de Buenos Aires en la república, Buenos Aires, La Facultad, 1936 [1912]. 
trarse en la figura intelectual de Juan Bautista Alberdi, reconocido como el principal inspirador doctrinario del texto constitucional a partir del proyecto de Constitución incorporado como capítulo XXXVII de la segunda edición de sus Bases y puntos de partida para la organización política de la República Argentina ${ }^{8}$. Conforme han advertido estudios recientes, esta identificación no puede ser escindida de una política editorial estatal que ya en 1855, y ostensiblemente hacia el año 1880, posicionaría a la doctrina liberal alberdiana en el centro de la tradición constitucional ${ }^{9}$.

La primacía de aquellas contraposiciones políticas eminentes -entre Buenos Aires y la Confederación, entre Sarmiento y Alberdi, entre el federalismo estadounidense y el vernáculo-, entendemos, ha desdibujado los rasgos de una circunstancia política más rica en matices, como la propia del conjunto de políticos, publicistas e intelectuales conocidos como los "hombres de Paraná"10, aquellos que, agrupados en torno a Urquiza, integraron el cuadro de las polémicas constitucionales desarrolladas en el seno de la Confederación Argentina. A pesar del ofrecimiento de Urquiza, Alberdi declinó el Ministerio de Hacienda para embarcarse en la tarea diplomática como Plenipotenciario de la Confederación Argentina ante las cortes de Francia, el Reino Unido, España y la Santa Sede. Mucha menos consideración retrospectiva ha recibido quien fuera entonces efectivamente primer Ministro de Hacienda de la Confederación: el cordobés Mariano Fragueiro, autor de Organización del crédito y Cuestiones argentinas ${ }^{11}$. Miembro del Gobierno Delegado de la Confederación Argentina conformado por Urquiza luego de la victoria de Caseros, continuó ejerciendo como primer Ministro de Hacienda de la Confederación luego de la sanción constitucional entre agosto de 1853 y septiembre de 1854.

La Constitución de 1853 dispuso, en su artículo 64 inc. $5^{\circ}$, que correspondía al Congreso "[e]stablecer y reglamentar un Banco Nacional en la Capital y sus sucursales en las provincias, con facultad de emitir billetes", receptando a su modo lo establecido tanto por el Pacto Federal de 1831 (art. 16, inc. 5) como el Acuerdo de San Nicolás (art. 2), que habían fijado a la deuda y al crédito nacional como uno de los

\footnotetext{
J. B. Alberdi. Bases y puntos de partida..., op. cit.

9 En 1880 se produce una publicación oficialmente ordenada de algunos textos doctrinarios de Alberdi, que versaban sobre derecho público y economía política: Esta interpretación alberdiana de la doctrina constitucional es afirmada como programa de gobierno por el mismo General Roca. Con él, la generación del 80 hace de la obra -e incluso de la figura- de Alberdi un punto de referencia de su proyecto político. Urquiza principia este movimiento de ideas en 1855, al decretar el gobierno nacional, "convencido de la benéfica influencia que ejercen en la opinión pública los escritos políticos y de derecho público argentino dados a luz por el ciudadano Juan Bautista Alberdi", la publicación de los textos iuspublicísticos y económicos de Alberdi, fijando de este modo "oficialmente" la corriente principal de la doctrina constitucional de la Confederación. Cf.: H. Tarcus, "La historia editorial como historia intelectual. Avatares de las ediciones de Juan Bautista Alberdi", en D. Quattrochi-Woisson, Juan Bautista Alberdi y la independencia argentina. La fuerza del pensamiento y de la escritura, Bernal, Universidad Nacional de Quilmes Editorial, 2012, pp. 153-176. Alejandro Herrero, “Alberdi, Bases y el gobierno de la Confederación Argentina en la década de 1850", en Épocas. Revista de Historia, $N^{\circ}$ 12, segundo semestre de 2015, pp. 47-68.

10 La fórmula "hombres del Paraná" aparece en la autobiografía de Lucio V. Mansilla, "diputado alquilón”-según la fórmula despreciativa porteña a los miembros bonaerenses- por Santiago del Estero en el Congreso de Paraná, y es recuperada por Roca en su "Carta-prólogo". Lucio V. Mansilla, Retratos y recuerdos, Buenos Aires, Imprenta de Pablo E. Coni, 1894, especialmente pp. 229-236. Cf. también: V. Gálvez (seudónimo de Vicente G. Quesada), Memorias de un viejo. Escenas de costumbres de la República Argentina, Buenos Aires, Solar, 1942 , pp. 191-227.

11 M. Fragueiro, Organización del Crédito, Santiago, Imprenta de J. Belín, 1850, y M. Fragueiro, Cuestiones Argentinas, Copiapó, Imprenta del Copiapino, 1852. En lo sucesivo referiremos a la edición conjunta: M. Fragueiro, Cuestiones Argentinas y Organización del Crédito, Buenos Aires, Solar/Hachette, 1976.
} 
objetos eminentes de arreglo constitucional. El proyecto constitucional alberdiano, sin embargo, no contemplaba la formación de un banco público; asunto que no había sido abordado, ni siquiera críticamente, en sus Bases. Sería por lo tanto la misma Constitución de 1853 la que sentaría las bases jurídicas de la polémica subsiguiente con el entonces Ministro Fragueiro. Esta cuestión, ausente en las elaboraciones alberdianas, constituía en cambio un motivo privilegiado de las Cuestiones argentinas de Fragueiro. Llegando allí a esbozar los lineamientos generales a adoptar por la Confederación, Fragueiro había insistido en la necesaria formación de una institución bancaria nacional que monopolizara las operaciones de crédito y de emisión de moneda, retomando de este modo los tópicos dilectos de su Organización del crédito. Con arreglo a dicha manda constitucional, el Ministerio de Hacienda encabezado por el cordobés presentó el 29 de noviembre de 1853 un "Proyecto de Estatuto para la Administración de la Hacienda y el Crédito Público" elaborado en colaboración con Juan María Gutiérrez, que sería aprobado por el mismo Congreso General Constituyente de 1852-53 en carácter de legislador ordinario. Precisamente en el año 1854 Alberdi publica su Sistema económico y rentístico de la Confederación Argentina según su Constitución de 1853 que constituye -y esta es una de nuestras hipótesis de partida- una réplica, por momentos feroz, al proyecto fragueriano. De este modo, la polémica entre Alberdi y Fragueiro es el primer conflicto de interpretación de un texto constitucional que, en su sentido jurídico eminente, perdura hasta nuestros días. Más aún, y como desarrollaremos en el próximo apartado, esta polémica pone en escena una oposición histórico-conceptual fundamental de la política contemporánea: aquella entre liberalismo y socialismo.

\section{Liberalismo y socialismo en la formación del momento constituyente}

Tal como señala Fabio Wasserman, si "[e]ntre 1750 y 1850 la familia conceptual liberal/liberalismo tuvo una importancia limitada en el discurso político rioplatense", es precisamente

a principios de la década de 1850 cuando comenzaban a coagular nuevos usos y significados que dotaron a "liberal" de mayor densidad conceptual, destacándose en ese sentido la progresiva difusión del neologismo "liberalismo" entendido como un indicador de movimiento temporal y como una fuerza o un sujeto histórico. [...] [F]ue justo entonces cuando "liberal" se constituyó en un "concepto histórico fundamental”'12.

Según este historiador, "[1]a Constitución podría considerarse entonces como piedra de toque del liberalismo argentino que en pocos años empezaría a dominar la vida política y la economía hasta bien avanzado el siglo XX"13.

12 F. Wasserman, "Liberal-Liberalismo", en J. Fernández Sebastián (dir.), Diccionario politico y social del mundo iberoamericano. La era de las revoluciones, 1750-1850 [Iberconceptos-I], Fundación Carolina-Sociedad Estatal de Conmemoraciones Culturales-Centro de Estudios Políticos y Constitucionales, Madrid, 2009, pp. 732-743, aquí p. 732.

13 F. Wasserman. "Entre la moral y la política. Las transformaciones conceptuales de liberal en el Río de la Plata (1780-1850)", en J. Fernández Sebastián (coord.), La aurora de la libertad. Los primeros liberalismos en el mundo iberoamericano, Madrid, Marcial Pons, 2012, pp. 37-74, aquí pp. 39 y 67. 
La centralidad que el concepto de liberalismo gana en los discursos políticos argentinos desde el momento constituyente de 1853 es contrastable con que Alberdi, como casi todos los miembros de la Generación del '37, fue receptivo en su juventud a las influencias ideológicas de una pluralidad de expresiones entre las que predominaba el socialismo republicano francés ${ }^{14}$. Sin embargo, hacia mediados de la década de 1840 Alberdi se aleja de sus posturas tempranas: a su primer viaje a Europa seguirá lo que Myers denominara su "giro absolutista" de 1843-4, que luego de las revoluciones europeas de 1848 lo llevaría a afirmar un "franco repudio" al socialismo ${ }^{15}$.

Es indudable que, desde lo ideológico, el ciclo revolucionario de 1848 moldea definitivamente los rasgos de los proyectos políticos para la Argentina posrosista elaborados por sus adversarios en la emigración ${ }^{16}$. Sin embargo, el significado que el '48 imprime sobre tales proyectos es menos homogéneo que el que en retrospectiva ha dominado. En efecto, si en las figuras de Alberdi o de Frías se verá un decidido giro hacia posiciones conservadoras, menos reparo se ha prestado a las posiciones de

14 En esta línea, Jorge Myers advirtió que "el republicanismo de la Nueva Generación [según sus referencias explícitas] adoptó (...) como vehículo el «socialismo» humanitarista de la escuela de Pierre Leroux”. J. Myers, "La revolución de las ideas: la generación romántica de 1837 en la cultura y en la política argentinas", en N. Goldman (dir.), Revolución, república, confederación (1806-1852), Buenos Aires, Sudamericana, 1998, pp. 381-445, aquí p. 429; cf. también: H. Tarcus. El socialismo romántico en el Río de la Plata (1837-1852), Buenos Aires, Fondo de Cultura Económica, 2016. Respecto al proyecto político alberdiano, Alejandro Herrero ha precisado que "[e]ntre 1837 y 1842 [Alberdi] planteaba, empleando sus palabras, una «república democrática» (siguiendo, sobre todo, los discursos exaltados de Leroux), que combinaba los principios de igualdad y de libertad proclamados por la revolución. [...] Invocaba la necesidad de un «dogma social» o «filosofía nacional» (esquema extraído de Leroux, Lerminier y Jouffroy), de una «economía democrática», es decir, planificada (adhería también aquí a Leroux), un Poder Ejecutivo fuerte (tomaba esta medida de Lerminier) y un Estado Federal (inspirado en las enseñanzas de Tocqueville) con el objeto de lograr la unidad nacional en un territorio donde predominaba la dispersión y la escasa población. Pero al mismo tiempo, Alberdi introducía argumentos de los doctrinarios y de Constant, para defender la libertad individual en oposición al Estado o sociedad que podía amenazarlo". A. Herrero, "Juan Bautista Alberdi: de la «república democrática» a la «república posible». Un proyecto alternativo al régimen de Juan Manuel de Rosas”, en Anuario del IEHS, N 17, 2002, pp. 261-290, aquí p. 262.

15 Alberdi afirmaría entonces que “el «socialismo» endilgado a la «Generación del ‘37» por sus enemigos nunca había sido tal, sino que era fruto de un equívoco provocado por la profunda ignorancia de esos adversarios". Desde entonces, "[p]ara Alberdi, «socialista» se refería no a un ideal «comunista»-de colectivización de la propiedad privada-, sino a un interés por la «sociedad» que a su juicio era enteramente compatible con una postura liberal. Sin embargo, si la primera parte de aquella descripción alberdiana es correcta, la segunda no lo es tanto. Su perpetuación como marco interpretativo de este período del pensamiento de la «Nueva Generación» ha servido para desdibujar los contornos originales del mismo, ya que si luego de 1848 el «liberalismo» de muchos miembros de esa generación se iría acentuando como marco ideológico de su reflexión, las características del mismo -en muchos casos contradictorias o sorprendentes- sólo se podrán explicar por su origen en un sistema de pensamiento que no era liberal, sino romántico, republicano, y «socialista»" (J. Myers, op. cit., p. 429).

16 Halperín Donghi ha indicado que tales proyectos se moldean sobre el telón de fondo de tres décadas de guerras emancipatoria y civil y casi dos de disolución de la antigua unidad política colonial, frente a los cuales se aparece una verdad irrecusable: la Argentina había consolidado su unidad política bajo la égida rosista. Los corolarios de este postulado, especialmente luego de la derrota política y militar de las coaliciones antirrosistas de la década de 1840 -en las cuales convergerían la emigración argentina con las potencias inglesa y francesa-, serían la revisión de su anterior posición como única élite competente en la dirección de los asuntos públicos, así como una nueva disposición a reconocer y pactar con las élites económico-sociales forjadas al calor del rosismo. Por otra parte, la adversidad a los efectos disolventes de las revoluciones del' 48 europeo los conduciría a un alejamiento de su temprano proletarismo y socialismo, y los impulsaría a abrazar diversas formas de conservadurismo político. Así, la "definición de un proyecto para una Argentina futura se daba en un contexto ideológico marcado por la crisis del liberalismo que sigue a 1848, y en uno internacional caracterizado por una expansión del centro capitalista hacia la periferia, que los definidores de ese proyecto se proponían a la vez acelerar y utilizar" (T. Halperín Donghi, op.cit., p. 9). 
Mariano Fragueiro: A contracorriente de la tendencia general, el ciclo revolucionario europeo impacta sobre el discurso de Fragueiro hasta hacerlo adoptar posiciones abiertamente socialistas, no presentes hasta entonces en sus publicaciones. Conviene remontarse al escenario chileno de la década previa para comprender mejor esto ${ }^{17}$.

Mariano Fragueiro ${ }^{18}$ había arribado a Chile hacia 1834 en un transporte que casualmente compartiera con Alberdi ${ }^{19}$, para desarrollar intereses mineros en Copiapó. Algo mayor que las generaciones románticas, se mantendría sin embargo en el ámbito de sus redes de socialización durante la emigración, y ya en 1840 le transmitiría al sanjuanino José Manuel Quiroga Rosas su admiración por Pierre Leroux ${ }^{20}$. Por gestiones comerciales, en 1841 pasaría brevemente a Buenos Aires, para retornar

17 El provincialismo historiográfico ha sido, en muchas ocasiones, responsable de una tara respecto a la justa comprensión de la marcha de las ideas durante la década previa a la sanción constitucional de 1853. Ciertamente, si desde un ángulo estrictamente rioplatense la historia política parece desconectarse de la historia intelectual, aquello que, recortado sobre el fondo de un "oscurantismo rosista", aparece plagado de rupturas y discontinuidades, se torna inteligible en nuevo grado al ser inscripto en su efectivo espacio de experiencia. Cf.: A. M. Stuven, "El exilio de la intelectualidad argentina: polémica y construcción de la esfera pública chilena (1840-1850)", en J. Myers (ed.), Historia de los intelectuales en América Latina I: La ciudad letrada, de la conquista al modernismo, Capellades, Katz, 2013, pp. 412-440; G. Rodríguez, "Exilio y comunidades intelectuales en los procesos de consolidación nacional. El impacto de la experiencia chilena en la trayectoria colectiva e individual de los hombres de la generación argentina de 1837”, en Estudios Trasandinos, N 16, Vol. 1, 2010, pp. 8-32.

18 Las noticias biográficas de Fragueiro se extraen de las siguientes fuentes: E. Martínez Paz, "Don MARIANO FRAGUEIRO. Noticia biográfica y crítica", en Revista de la Universidad Nacional de Córdoba, Año 17, $\mathrm{N}^{\circ}$ 3-4, Segunda Parte, Mayo-Junio de 1930, pp. 3-64; J. A. Solari, Una figura patricia: Mariano Fragueiro. Buenos Aires, Editorial Centro de Historia Mitre, 1947. La principal fuente sobre la trayectoria vital de Fragueiro es un prospecto biográfico que, según demuestra G. Weinberg, consiste realmente en una autobiografía ("Apéndice [Autobiografía]", en M. Fragueiro, op. cit., pp. 100-110.

19 Ante la proximidad del segundo Gobierno de Rosas, Fragueiro tramitó y consiguió en 1834 sus pasaportes ante el gobernador Viamonte. Según relata Alberdi en su autobiografía, "[e]n el mes de Junio de ese mismo año de 1834, pasé a Tucumán, teniendo por compañeros de viaje, entre otros sujetos agradables, a mi amigo don Juan Avellaneda y a don Mariano Fragueiro, que se encaminaba para Bolivia. Hacíamos el viaje en una diligencia o carruaje de cuatro ruedas, tirado por caballos, de propiedad privada de mi paisano y amigo don Baltasar Aguirre. Para entretener el tiempo, nos leía don Mariano Fragueiro el Viaje del Capitán Andrews, hecho al través de nuestras provincias del Norte, por cuenta de una compañía inglesa de minas, en 1825. El señor Fragueiro lo traducía del inglés al tiempo que lo leía. Nos había leído todo lo relativo a Santiago, a Tucumán, a Salta y hasta Potosí, menos a Córdoba, el país nativo del lector. ¿Por qué omitía lo que más nos interesaba, pues era el pueblo que acabábamos de habitar? — De temor de leernos, confesó el señor Fragueiro, la crítica amarga que de muchas cosas de la sociedad de su provincia había hecho el viajero protestante, que la visitó en 1825 ” (J. B. Alberdi, "Mi vida privada, que se pasa toda en la República Argentina", en J. B. Alberdi, Escritos Póstumos, Tomo XV, Buenos Aires, Imprenta Juan Bautista Alberdi, 1900, pp. 261-312, aquí pp. 284-285). En el relato de Andrews, Mariano Fragueiro merece una mención especial: se trata, según el capitán, de una de los pocos "caracteres públicos" que se oponen a la retardataria situación cordobesa. J. Andrews. Journey from Buenos Ayres, through the provinces of Cordova, Tucuman, and Salta, to Potosi, thence by the deserts of Caranja to Arica, and subsequently to Santiago de Chili and Coquimbo, undertaken on behalf of the Chilian and Peruvian mining association, in the years 1825-26, Vol. 1, Londres, John Murray, 1827, pp. 70, 74-75.

20 José Manuel Quiroga Rosas escribe desde Copiapó a Alberdi: "Después de llegado aquí, a los pocos días, tuve la felicidad de haber conseguido conmover un poco la emigración argentina, tanto por lo que respecta a nuestras ideas; como por lo que respecta a nuestra política de circunstancia. Vamos por parte (sic): el Catecismo ha agradado sobremanera a estas gentes enfermas y deseosas de elevarse. Tenían la peor idea de la juventud de Buenos Aires y su resignación a la desgracia, llegaba a su colmo. Hoy es otra cosa. D. Mariano Fragueiro y otros, creyeron al principio que el Catecismo sería de Rivadavia, luego que les hablé circunstanciadamente de todo, vieron su desengaño, que más se afirmó cuando vieron los trabajos continuos de la juventud, durante la Tiranía y cuando conocieron las páginas de nuestro maestro Leroux. Fragueiro dice que no quisiera ir a Francia, sino para ver a Leroux, que los negocios públicos de nuestra República, después de un cambio, debían dejarse libremente a la capacidad de la juventud. Es esta una completa conquista o no? Ya se vé, no era difícil hacerla en un espíritu tan despejado y en un corazón tan generoso, tan nuevo." Carta de Quiroga Rosas a Alberdi, 1/7/1840, en J. B. Alberdi, Escritos póstumos, Tomo XV, Buenos Aires, Imprenta Juan Bautista Alberdi, 1900, pp. 369-370. 
pronto a Copiapó. En 1848, con el aparente motivo de una enfermedad de su esposa, Fragueiro se establecería en Buenos Aires, para regresar a Chile en 1849.

El Chile de la década de 1840 estaría indudablemente signado tanto por la consolidación de la emergente "cuestión social" 21 , como por un sistema autoritario en la esfera cultural desde que, con el asesinato de Portales (1837), el régimen conservador intensificara la persecución contra los intelectuales liberales -los que, por su parte, lanzarían feroces respuestas como Guerra a la Tiranía-. En este cuadro, la Generación o Movimiento Literario del $42^{22}$ se lanza a la esfera pública en una serie de polémicas públicas -entre otras, la de la oposición entre romanticismo y clasicismo- que cristalizarían parcialmente en la efímera Sociedad de Literatura de Santiago; a diferencia de su contrapartida en el Plata -el Salón Literario de Marcos Sastre-, aquélla contaría con los buenos oficios de Andrés Bello, arquetipo del moderno letrado americano y principal intelectual del régimen. La contraposición entre conservadores y liberales, que había estructurado el escenario político-intelectual chileno desde las guerras civiles, sentó las bases para a la aparición de un nuevo campo que, desde mediados de la década, comenzaría como una escisión del liberalismo hasta condensar un lenguaje socialista y republicano ${ }^{23}$. Se trata de un movimiento excéntrico -o des-centrado, como sugiere Illanes- no sólo desde el plano ideológico -en el que las tendencias socialistas francesas ocuparían un lugar central-, sino también por su misma estructuración como una respuesta a la modernización capitalista liberal y a la centralización administrativa desplegada por la larga década conservado$\mathrm{ra}^{24}$. El revolucionario ensayo Sociabilidad chilena, publicado en 1844 por Bilbao, es un claro exponente de la nueva época: por su publicación, el autor fue sometido a juicio por su escrito "blasfemo e inmoral", perdió su empleo de Profesor en el Instituto Nacional, y acabó en un exilio autoimpuesto; la obra, por su parte, sería "quemada por mano del verdugo"25.

Esta es también una época de transformaciones en el campo de la economía política, tanto por la recepción de la nueva "economía social" como por su proyección sobre el debate en torno a la reforma de las instituciones: las propuestas de creación de un Banco Nacional, cuyos antecedentes se remontan a las primeras décadas posrevolucionarias, están nuevamente a la orden del día ${ }^{26}$. En el diario El Progreso

21 L. A. Romero, “Urbanización y sectores populares: Santiago de Chile, 1830-1875”, en Revista EURE - Revista De Estudios Urbano Regionales, Vol. 11, No 31, 1984, pp. 55-66; S. Grez Toso, La cuestión social en Chile: Ideas y debates precursores (1804-1902), Santiago de Chile, DIBAM, 1997; L. A. Romero, ¿Qué hacer con los pobres? Elite y sectores populares en Santiago de Chile 1840-1895, Buenos Aires, Editorial Sudamericana, 1997.

22 Acerca del movimiento, cf. el número especial por su centenario de Revista Atenea: Atenea. Revista mensual de ciencias, letras y arte, Año XIX, tomo LXVIII, No 203, Universidad de Concepción, 1924.

23 C. Gazmuri, El “48” chileno igualitarios, reformistas radicales, masones y bomberos, Santiago de Chile, Editorial Universitaria, 1999, pp. 28-35; M. A. Illanes O., Chile des-centrado: formación socio-cultural republicana y transición, Santiago de Chile, LOM Ediciones, 2003.

24 M. A. Illanes O., op. cit., p. 179 y ss.

25 S. Grez Toso, op. cit., pp. 14-15.

26 Como señala José Edwards, "la creación de un banco nacional venía siendo debatid desde la época de Anselmo de la Cruz, Camilo Henríquez y José Joaquín de Mora (1810s-20s) (...) La concentración de la riqueza entre [las] clases comercial y terrateniente, la inequidad en la distribución de la propiedad y el monopolio del capital y el crédito, motivaron un pensamiento económico de carácter social en el que destacaron Pedro Félix Vicuña (1805-1874) y en menor medida el argentino Mariano Fragueiro (1795-1872), Francisco Bilbao (1823-1865) y Santiago Arcos (1822-1874) (hijo de Antonio Arcos)". J. Edwards, "La historia del pensamiento económico en Chile (1790s-1970s)", Open Science Framework, p. 10, disponible en: https://osf.io/vdxf9 
de Santiago ( $\mathrm{N}^{\circ}$ 575) aparecen "Reforma que conviene adoptar en los Bancos" y "Proyecto para un Banco de Chile"; en debate impulsado por Bernardo José de Toro Guzmán, el tema se discute en la Cámara de Diputados en septiembre de $1844^{27}$. En 1845 Fragueiro publica sus Fundamentos de un proyecto de banco ${ }^{28}$-una reedición de su propuesta a la Sociedad de Agricultura efectuada el año anterior-, y da a la luz sus complementarias Observaciones sobre el proyecto de estatuto para el Banco Nacional de Chile ${ }^{29}$. El punto de partida de la argumentación fragueriana consiste en que "[1] os Bancos vienen a ser una institución social: (...) la más sencilla de sus operaciones es pública y sus efectos necesariamente trascendentales: no pueden oponerse ni aún separarse de la marcha de la civilización: siguen las leyes del progreso"30. Consideradas desde este ángulo histórico-filosófico, según Fragueiro

[1]as instituciones de crédito son al estado presente de las sociedades, lo que la introducción de la moneda fue en su época. La moneda ha influido en la civilización tal vez como uno de los primeros resortes. Ella y el fierro han puesto a la generalidad de los hombres en capacidad de emplear sus facultades del modo más ventajoso para sí, y para sus semejantes. La industria, y la propiedad que es su consiguiente, deben a estos poderosos resortes todo lo que son; del mismo modo que la especie humana ha elevado los grados de su poder y de su dignidad moral apoyándose sobre la industria. Si la civilización europea debe algo al descubrimiento de América, es razonable buscar la causa en el oro y plata que se introdujo en aquellos mercados, estimulando las facultades de todos, animando la industria, y aumentando la propiedad ${ }^{31}$.

El conocimiento de la lógica que rige la marcha de la civilización económica permite, por lo tanto, apropiarse de la experiencia principiada por los pueblos de Europa, a fin de evitar los errores cometidos por aquéllos, y multiplicar por lo tanto sus rendimientos benéficos en estas Repúblicas:

Los pueblos europeos también principiaron su carrera del mismo punto de partida que nosotros; y no con un porvenir tan auspicioso; porque no perteneciendo a la actual civilización no tenían ni las tradiciones, ni las experiencias nuestras y sin embargo han encontrado crédito, y se han endeudado monstruosamente aplicando los capitales a la conquista y disipaciones. ¿Por qué no podrán los gobiernos americanos endeudarse para ponerse con esos capitales al frente de la industria? [...] Si pues es una realidad que el gobierno de Chile, como todos los de América, se ha endeudado, y no se encuentra inconveniente en que esta deuda siga hasta hacerse con el tiempo del tamaño de las de los gobiernos europeos ¿porqué se duda que él mismo puede realizar los fondos destinados al Banco? ¿Porqué pagando rentas, que se sacan de la miseria del pueblo, la deuda pública, puede ascender indefinidamente y acumular guarismos que no se comprenden, y pagando rentas, que saldrán de la reproducción, no podrán acumularse capitales que nos asombren

\footnotetext{
Congreso Nacional de Chile, Sesiones de los Cuerpos Lejislativos de Chile, Tomo XXXIV, 1844, pp. 358 y ss. M. Fragueiro, Fundamentos de un proyecto de banco, Santiago de Chile, Imprenta del Siglo, 1845.

29 M. Fragueiro, Observaciones sobre el proyecto de estatuto para el Banco Nacional de Chile, Valparaíso, Imprenta del Mercurio, 1845, p. 18.

30 M. Fragueiro, Fundamentos..., op. cit., p. 8.

31 Ibidem, p. 44.
} 
también? [...] Que esas diarias y multiplicadas economías formen el capital de Banco y el tiempo hará de este establecimiento un monstruo de riqueza como ha hecho deudas monstruosas ${ }^{32}$.

El recurso a las instituciones de crédito como medio eminente para la reforma progresiva de la sociedad sería un componente fundamental de los discursos sainsimonianos, y su legado se proyectaría sobre el socialismo fraternario francés de la década de 1840. La propuesta de Fragueiro se distingue por sugerir que para su correcto desenvolvimiento ("para que los bancos verifiquen todas las ventajas que ofrecen, y que no caigan en abusos y errores"), las instituciones de crédito deben ser administradas

por un cuarto poder político independiente, como los tres ya conocidos en los Gobiernos constitucionales. Sobre esta parte de mi Proyecto pido una atención especial; y tanto más, cuanto que la estimo como esencial, y como la única base sine qua non. Con una organización semejante no solo el Banco quedaría libre de las influencias que lo arrastran a cometer abusos, sino que también los soberanos llenarían las exigencias de este siglo industrial, colocándose al frente de la industria nacional, y aliviarían los dolores que aquejan a las sociedades, generalizando los medios de producción ${ }^{33}$.

\section{Fragueiro, el 48 europeo y su plan constitucional}

Precisamente en el año 1848 se inicia en Chile un movimiento de contestación a los renovados intentos de perpetuación del bloque conservador ${ }^{34}$. La aparición del Club de la Reforma (1849), y su continuación en la más radicalizada Sociedad de la Igualdad (1850) capitaneada por Santiago Arcos y Francisco Bilbao, se inscriben en un ciclo de alza del movimiento revolucionario en Chile que alcanzaría su cénit en la revolución de $1851^{35}$. Es en este álgido contexto que ve la luz la obra doctrinaria

32 Ibidem, p. 8

33 Ibidem, pp. 2-3. La autoría de esta revolucionaria propuesta de elevar el crédito al rango de un cuarto poder constitucional sería motivo de una polémica con Vicuña (Cf.: P. F. Vicuña, Cartas sobre Bancos, recopiladas de las que ha insertado el Mercurio de Valparaíso, escritas por d. Pedro Félix Vicuña, Valparaíso, Imprenta del Mercurio, 1845, y M. Fragueiro, Fundamentos..., op. cit., pp. 89-98).

34 C. Gazmuri, op. cit., pp. 36 y ss.; P-L. Abramson, "La Revolución chilena (1848-1852)", en P-L. Abramson, Las utopías sociales en América Latina en el siglo XIX, México, Fondo de Cultura Económica, 1999, pp. 91-120.

35 El programa reformista de la Sociedad de la Igualdad aparece plasmado con claridad en el siguiente pasaje del periódico La Barra, redactado por Francisco Bilbao en respuesta a una crónica de la Revista de Santiago: “¿Sabéis cuál es la cuchilla que entregamos a la Sociedad de la Igualdad? Es esta: Respetemos a nuestros enemigos; - abolición de la pena de muerte y de la pena de azotes, conquistemos la justicia con la razón y la asociación pacifica — nada de violencia — ¿Sabéis cuales son las venganzas que pedimos? son estas: olvidemos los odios políticos para no ocuparnos sino del bien del pueblo - olvidemos las cárceles y destierros de los estados de sitio para pedir libertad y garantías para todos. ¿Sabéis las carnicerías que invocamos la muerte de la miseria, de la usura, la muerte del vicio, del odio, la muerte del mal. Queremos la vida - somos hombres de fraternidad y queremos ver el reino de la justicia acá en la tierra. Y es por esto que se nos injuria, es por esto que se nos calumnia? Creemos, pedimos el sufragio universal, llamamos a todo chileno o la vida de la patria - pedimos instituciones de crédito para que hagan real la soberanía del hombre y mientras tanto procuramos organizar las asociaciones de los pobres entre sí, para que la fraternidad sea nuestra riqueza-i que el centavo del pobre venga en auxilio del desgraciado. ¿Y cómo se responde, cómo se protege esta obra que emprendemos? Llamándonos comunistas 
fundamental de Fragueiro, Organización del crédito (1850), en la que pretende fundamentar sistemáticamente la superación de la "aristocracia industrial" en favor de una "democracia industrial" por medio de la formación de un monopolio público del crédito instituido como un cuarto poder del Estado. En detrimento de la "tiranía del capital" sobre la prensa, a la que acusa de constituir una efectiva "censura previa" dictada por el interés empresarial, propone también la impresión de obras declaradas de interés público en imprentas estatales financiadas mediante el monopolio de la impresión de avisos públicos. Su publicación no pasó inadvertida en los círculos intelectuales chilenos: la Revista de Santiago, por un lado, le dedicó dos recensiones centradas en la dimensión económica ${ }^{36}$; Bartolomé Mitre, desde Los Debates, le dedicaría un comentario polémico centrado en la libertad de prensa y la cuestión de la censura previa ${ }^{37}$. Aunque publicada en 1858 , Vicuña redacta en las postrimerías de 1851 su El porvenir del hombre -cuyo subtítulo rezaba "relación íntima entre la justa apreciación del trabajo y la democracia"-, en el que habría de insistir en el papel del monopolio público del crédito para la democratización universal, en vistas de una inminente revolución impulsada por los falsos principios de la economía política liberal y del comunismo ${ }^{38}$.

Durante la primera mitad del siglo XIX, liberales y socialistas franceses habían discutido sobre la hipótesis del desacompasamiento entre el crecimiento de la población y los medios de subsistencia elaborada por Malthus en la década de $1780^{39}$ : sería esta discusión la que habría de proveer la clave fundamental de interpretación del nuevo conflicto de la época, tanto para diagnosticarlo como para pronosticar los medios de su superación. Jean Baptiste Say, en su Tratado de Economía Política -que entre 1826 y 1829 fuera la base bibliográfica del curso de Economía Política a cargo de Vélez Sarsfield en la Universidad de Buenos Aires-, había hecho suyas las pre-

— niveladores — diciendo que llamamos a carnicerías y a venganzas." F. Bilbao, "A la Crónica de la Revista de Santiago", en La Barra. Diario político y cultural, Año 1, No 32, 11 de julio de 1850, Santiago de Chile, pp. 2-3.

36 Revista de Santiago, T. VI, octubre-diciembre de 1850, pp. 411-413; M. A. Matta, "Organización del Crédito", en Revista de Santiago, T. VII, diciembre de 1850 a abril de 1851, pp. 46-55.

37 "Es de admirar que siendo el libro del señor Fragueiro una enérgica y valiente protesta contra la tiranía del capital y la explotación del trabajo, el sistema que él nos proponga en su lugar sea un sistema de restricciones, en que la tiranía del capital es reemplazada por la tiranía del crédito, la tiranía del Estado y por la tiranía de la ley, mil veces más insoportable que la del individuo, como lo prueba la organización de la república veneciana. [...] Según él cuestión de libertad de imprenta es cuestión de propiedad, y su solución debe buscarse en el uso de propiedad, así como la imprenta, es decir la fábrica, debe organizarse por las leyes del trabajo. [...] Lo primero que propone el nuevo reformador socialista es que se establezcan imprentas por cuenta del Estado, que hagan concurrencia a las imprentas particulares; funestos principios de economía, que los socialistas han sido los primeros en repudiar, después de la desgraciada tentativa de Talleres nacionales en Francia, después de la revolución de febrero. Luego declara exclusiva de la imprenta del Estado la publicación de los documentos oficiales, avisos y toda otra noticia tomada de las oficinas públicas. Donde haya imprenta habrá jurado. Obligación del jurado será tasar el valor de todas las producciones que se publiquen, y a más (oíd) declarar si es útil o no todo escrito que le sea sometido, antes de su publicación, para que declare si debe o no imprimirse. He aquí la censura previa." Bartolomé Mitre, "Bibliografía. Organización del Crédito. Censura Previa", en T. Halperín Donghi (comp.), Proyecto y construcción de una nación (Argentina 1846-1880), op. cit., pp. 189-192 (original en Los Debates, Buenos Aires, 22 de mayo de 1852). Fragueiro replicará en su Cuestiones Argentinas que la publicación en las imprentas estatales de obras declaradas de interés público por parte de un jurado no constituye un óbice para su publicación por la prensa privada. M. Fragueiro, Cuestiones Argentinas y Organización del Crédito, op. cit., pp. 128-129.

38 P. F. Vicuña, El porvenir del hombre, Santiago de Chile, Biblioteca Nacional-Pontificia Universidad Católica de Chile-Cámara Chilena de la Construcción, 2010.

39 Y. Charbit, "Du malthusianisme au populationnisme. Les «Economistes» français et la population (18401870)", en Population, Año 36, № 2, 1981, pp. 287-293. 
venciones maltusianas sobre la evolución poblacional: aunque la realidad desmintiera la precisión de sus pronósticos, las tendencias generales de la vida social parecían marchar sin embargo en esta línea ${ }^{40}$. Sismondi también había evaluado la teorización malthusiana pero, desligándola de una necesidad natural, habría de proponer medidas fiscales que debían paliar efectos propios de la lógica capitalista. Pellegrino Rossi aceptaría en líneas generales las previsiones teóricas de Malthus, destacando sin embargo que ciertas inclinaciones humanas desarrolladas con el perfeccionamiento social morigeran su fatalidad, de modo que con el pasaje de la barbarie a la civilización -y en especial, a partir de la difusión de la instrucción moralizante entre los trabajadores- es posible alcanzar cierto equilibrio entre la reproducción de la población y sus consumos ${ }^{41}$. Algunos años después, en torno a los agitados días de 1848, los socialistas como Leroux y Proudhon también discutirían las tesis maltusianas en vistas del novedoso conflicto social que entonces parecía alcanzar su cénit: si el segundo, luego de un severo examen crítico, la vería como inexorable ${ }^{42}$, el primero insistiría en su superación por medio de la reforma social que debía abolir la plutocracia ${ }^{43}$.

Desde este ángulo, el estallido del ciclo revolucionario de 1848 sería más bien la manifestación de un conflicto que, subrepticiamente, venía desarrollándose en el seno de la sociedad. El pauperismo de las masas trabajadoras es entonces una de las principales preocupaciones de la Asamblea Constituyente de la República Social y Democrática en Francia: una batería de medidas, como los efímeros Talleres Nacionales basados en el modelo de la Organización del trabajo de Louis Blanc ${ }^{44}$ o el proyecto de constitucionalización del Crédito Social propugnado por Lamennais y Berbet $^{45}$, se dirigen precisamente a avanzar sobre su superación. Desde esta perspectiva, la unidad del desenvolvimiento histórico hace converger a la historia pasada y el diagnóstico de la crisis presente con una prognosis que impacta sobre los proyectos sociopolíticos para la Confederación Argentina.

Para Alberdi los acontecimientos de 1848 son motivo de una cabal confirmación de la conciliación espontánea entre intereses americanos y europeos: mientras que, en una América del Sur atormentada por las vastas extensiones despobladas, la tragedia consiste en la carencia de población, el drama europeo es precisamente el opuesto. Así, será después de 1848 que Alberdi formularía su célebre ley de "dila-

40 "Hay sufrimientos, que nacen de la naturaleza del hombre y de las cosas. El excedente de la población sobre las posibilidades necesarias para su mantenimiento pertenecen a este grupo. Esta desgracia, más o menos, tan grande en sociedades civilizadas como en tribus salvajes. Echar la culpa de ello al orden de la sociedad es injusto. Imaginarse que pudiese ser posible de liberarse de ello es una ilusión. Trabajar para atenuar esta desgracia es una ocupación noble. Pero no se debe buscar un remedio que no curará nada o cuyos efectos secundarios son más graves que la desgracia misma" (J. B. Say, Traite d'economie politique, Vol. II, Cap. VII, Bruselas, C. J. de Mat Fils et H. Remy, 1827, p. 188 [traducción nuestra]).

41 P. Rossi, Curso de economía politica, Madrid, Boix editor, 1840, pp. 306-387.

42 Y. Charbit, "Proudhon et le piège malthusien", en Cahiers internationaux de sociologie, Vol. 116, № 1, 2004, pp. 5-33.

43 P. Leroux, De la ploutocratie, ou du gouvernement des riches. Nouvelle édition, Bousac, Impremierie de Pierre Leroux, 1848, pp. 239-243; P. Leroux, Malthus et les économistes ou Y aura-t-il toujours des pauvres? Nouvelle édition, Boussac, Impremierie de Pierre Leroux, 1849 (se trata de una reproducción de los artículos de la Revue sociale publicados bajo el título "De la recherche des biens matériels, ou de l'individualisme et du socialisme" entre noviembre de 1845 y mayo de 1846).

44 L. Blanc, Organization du travail (Cinquiéme edition), París, Bureau de la Sociéte de l'industrie fraternelle, 1847.

45 F. R. de Lamennais y Auguste Barbet, Projet de constitution de crédit social (Extrait du Peuple Constituant), París, Bureau du Peuple Constituant, 1848. 
tación del género humano" que habría de regir el "desarrollo de la civilización cristiana y moderna", y que provee el fundamento del programa político de sus Bases. De acuerdo a esta ley, cuyo "fin providencial" es "el mejoramiento indefinido de la especie humana, por el cruzamiento de las razas, por la comunicación de las ideas y creencias", las migraciones, por imperio de "la nivelación de las poblaciones con las subsistencias" ${ }^{46}$, son el elemento de equilibrio de una única civilización desplegada entre dos continentes.

A diferencia de Alberdi, Fragueiro verá en estos acontecimientos europeos la ratificación de las ideas de reforma social bosquejadas unos años antes en sus publicaciones sobre la reforma del crédito en Chile: Así, en su Organización del Crédito de 1850 sostiene que "[e]s verdad que entonces, no siendo prácticas en la sociedad mis ideas, no las manifesté con la extensión y seguridad con que lo hago ahora, al ver que aquéllas se repiten en Europa" ${ }^{47}$. De modo que, con posterioridad a los acontecimiento de 1848, el discurso fragueriano gana rotundez en sus ribetes socialistas.

La visión histórico-filosófica progresiva de Fragueiro aparece condensada en los "Preliminares" de Organización del Crédito. Allí el autor afirma, en un pasaje que con meridiana claridad resume su postura, que

[c]ada época refleja el contingente de leyes naturales conocidas. Hoy tenemos de ellas un registro más extenso que nuestros antepasados; los siglos venideros encontrarán ese código aumentado con la adquisición presente, más las nuevas que se hicieren; y así, progresivamente, la razón humana se acercará al conocimiento de lo que debe ser la vida de la humanidad; al conocimiento de las leyes que establecen la armonía entre Naturaleza, Hombre y Sociedad. Estos tres grandes elementos del bienestar de los hombres obran de consuno y concurren por leyes fatales al mismo resultado. El hombre sin la sociedad es un ser errante, sin libertad, sin poder, sin medios de subsistencia, sin deberes ni derechos; no es persona. La sociedad no puede suprimir la individualidad; no puede hacer del hombre dotado de voluntad un instrumento pasivo. El individuo y la sociedad no pueden separarse de las leyes de la naturaleza, porque sufrirán reacción. Así es que estos grandes agentes, sirviéndose ya de nuestros aciertos, ya de nuestros errores, nos conducen en último fin hacia esa armonía de naturaleza, hombre y sociedad; marchamos, a pesar nuestro, a la civilización, pues que por civilización no debe entenderse otra cosa que la relación mejor organizada entre el individuo y la sociedad bajo de las leyes de la naturaleza. Esto sería el orden natural de las sociedades. He aquí la incógnita que el siglo trata de encontrar para remediar los males que afligen física y moralmente a la humanidad; para curar la llaga universal de las sociedades: el pauperismo forzoso. La rebelión de los pueblos más antiguos y cultos, la inquietud de sus gobiernos, la anarquía en todas partes, el malestar de cada uno, nos revela una agitación universal, que no es otra cosa que la falta de orden y armonía social. Otra vez no faltaron sectarios de Malthus que con él miraban la peste, el hambre y la guerra, esas terribles plagas del vicio y desorden de la sociedad, como leyes naturales, para establecer el equilibrio entre la población y la subsistencia. Pero al mismo tiempo aparecieron escritores que derramaron la caridad de sus generosos corazones contra tal inculpación a la bondad de la Providencia; y, llenos de fe

46 J. B. Alberdi, Bases y puntos de partida..., op. cit., pp. V-VII (grafía actualizada).

47 M. Fragueiro, Cuestiones Argentinas y Organización del Crédito, op. cit., p. 185. 
en los designios del Creador, buscaban el mal en algún vicio de la organización social, y pronosticaban la pronta justificación de las leyes del Padre común de la humanidad. Y en efecto la Europa principia a buscar en el socialismo la solución que no ha encontrado en el individualismo. Esta base de la civilización actual amenaza ruina. La tendencia de las ideas es a construir nuevos fundamentos sociales, sobre los que debe levantarse una civilización nueva también. Se apuran las cuestiones de economía política como exclusivamente sociales, y las únicas eficaces para conciliar todos los intereses sobre el interés común ${ }^{48}$.

Según la argumentación que entonces desarrolla Fragueiro, el signo de la época es el de la aparición de nuevas líneas de fractura en la vida social, tanto en el seno de la misma sociedad como entre la sociedad y su gobierno político: la esfera social, concebida a la luz de las relaciones de propiedad, se fractura entre una "aristocracia industrial" y las masas pauperizadas; la animadversión política de esas masas proletarias sólo vinculadas al gobierno por el tributo de su sangre, motoriza luego una fractura entre el poder político y la sociedad. De acuerdo a Fragueiro, la causa profunda que anima al conflicto político de la hora, en realidad, se reconcentra en las cuestiones de propiedad:

Todos los partidos políticos, que han turbado la sociedad, son cuestiones de propiedad. Los pueblos del viejo mundo, tan civilizados como industriosos, ¿por qué se convulsionan? ¿por qué las revoluciones tienen en todas partes y en todos tiempos el mismo carácter? Sin duda porque la humanidad está bajo de la influencia de leyes generales, y las mismas causas deben producir los mismos efectos, modificados solamente por los accidentes peculiares de cada pueblo. Las revoluciones son el cumplimiento de la ley de la reacción igual a la acción. Son el individuo y la sociedad procurando la armonía entre ambas partes para establecer el orden social. Individualismo y socialismo son los dos únicos partidos en que se refunden todas las clasificaciones ${ }^{49}$.

Por lo tanto, según Fragueiro, "[e]1 orden social y la riqueza misma se interesan en que el mayor número de hombres tenga participación en la civilización. Esta participación no puede obtenerse sino por la distribución de la riqueza"50. Respecto a las posibilidades futuras del desenvolvimiento de la civilización bajo el socialismo, afirma el cordobés que

[1]a civilización actual es el producto de la inteligencia humana, diseminada e individualmente obrando. ¿Cuál será el producto de la unidad de esa inteligencia? Instrucción y capital son la palanca y el punto de apoyo: si ambos se socializan, si se difunden y si el pueblo los toca no más, ¿quién se atreverá a medir su curso y a pesar sus fuerzas? Los progresos de la actual civilización son grandes en verdad; pero se han sucedido lentamente en razón de los esfuerzos de la tendencia natural, encontrados y detenidos en el individualismo; la humanidad ha marchado pero a pasos contados. La tendencia progresiva del hombre, sin aquellos inconvenientes,

\footnotetext{
48 Ibidem, pp. 181-182 (subrayado nuestro).

49 Ibidem, p. 185.

50 Ibidem, p. 205-206.
} 
y allanado el camino por el socialismo y por las instituciones que le acompañan, acelerará su marcha, y sus progresos serán a pasos desmedidos ${ }^{51}$.

La unidad del desenvolvimiento histórico que ha conducido hacia la pauperización de las masas europeas y a la intensificación del conflicto socio-político, por lo tanto, le motiva serias prevenciones respecto a los efectos de una potencial inmigración: en oposición a Alberdi, Fragueiro advierte que de mantenerse las causas del pauperismo de las masas europeas, su réplica en Sudamérica será su efecto inevitable. De mantenerse las condiciones de apropiación particularista de la riqueza social, "es imprudente y peligroso promover la inmigración. En más o menos tiempo nos encontraremos tan repletos como la Europa lo está. La población sin capital y sin medios de trabajar, es onerosa más bien que productiva; es preciso antes hacer que los capitales se subdividan y muden de manos"52. Incluso más, de cara al desafío del poblamiento de los "inmensos desiertos que aterran al hombre civilizado", Fragueiro advierte que no "debemos contar como un recurso, para anticipar el tiempo, con la inmigración europea; la que por sus hábitos preferiría siempre fijarse en las ciudades y poblaciones que ofrezcan más seguridad y comodidad". En la confianza de que "[e]l Evangelio y el capital son la idea y la acción civilizadoras del hombre", Fragueiro recomienda en sus Cuestiones Argentinas "reconocer a [a los indígenas] el derecho de propiedad al terreno que ocuparen, e intervenir en su distribución entre los varios propietarios", así como "educarlos en la doctrina y práctica del Evangelio" a fin de que "conozcan las ventajas del poder social, que da a cada uno lo que es suyo" 53 . En suma, el punto de partida de Fragueiro es el de la afirmación de una verdadera unidad de la lógica que rige el despliegue civilizatorio a escala planetaria, de modo que la situación europea no es más que la imagen anticipatoria del futuro argentino de no mediar una reforma. De modo que el anticiparse a los efectos socialmente disolventes de una apropiación particularista de las grandes capacidades económicas de la sociedad industrial lo motiva a promover la reforma social por medio de la socialización del crédito, que derogue la "aristocracia industrial" en favor de la "democracia industrial".

En la argumentación desplegada por Alberdi en torno a la Constitución del Estado de California como el paradigma al que debe apuntar el constitucionalismo hispanoamericano se hace manifiesta la orfandad de su visión económico-política. En el capítulo XII de sus Bases... el tucumano presenta a dicha Constitución como "la confirmación de nuestras bases constitucionales" 54 , atribuyendo la veloz prosperidad de dicho Estado a su liberalidad respecto a la concesión de garantías jurídicas sin discriminación de origen ni exigencias de nacionalización. Lo que Alberdi parece no advertir es, precisamente, que en el mismo año de 1848 en que la derrota mexicana obligara a ceder dicho territorio a los Estados Unidos se produjo el inicio de la "fiebre del oro". Como pronosticaban Marx y Engels hacia 1850, se iniciaba entonces un desplazamiento del eje de acumulación capitalista que transformaría a la totalidad del planeta ${ }^{55}$.

Frente a la confianza ilimitada en las virtudes de la importación institucional, Fragueiro advertiría que

\footnotetext{
Ibidem, p. 280.

Ibidem, p. 290

Ibidem, pp. 133-134.

J. B. Alberdi, Bases y puntos de partida..., op. cit., p. 46.

K. Marx y F. Engels, "El oro californiano. Canales en América Central”, en Karl Marx y Friedrich Engels, $M a-$ teriales para la historia de América Latina, Córdoba, Ediciones de Pasado y Presente, 1972, pp. 191-197.
} 
[s]e atribuye la prosperidad de las naciones a su forma de gobierno, a su constitución y a sus actuales instituciones; y andamos al tacto imitando la civilización de la Europa y la libertad de Estados Unidos, como si el bienestar de los pueblos dependiera de formas y palabras, y entretanto olvidamos que el trabajo organizado es la base de la sociedad, y que esa organización no puede encontrarse sino en la originalidad e independencia de cada nación ${ }^{56}$.

Sin llegar a un pronóstico tan preclaro como Marx y Engels, el cordobés habría de afirmar que

[e]l ejemplo de los Estados Unidos y de otros países nuevos nada prueban. Se ve la prosperidad de ellos, y el buen éxito de la emigración se atribuye con ligereza a la constitución, a las instituciones y a la población; pero se olvida que en esos países, el capital, que es la tierra, los bosques, los pastos, los ríos, etc., está prodigado por la naturaleza [...] Más cuando la población llegue al período en que todo esté poseído con exclusión, como lo pide el orden social, no serán ya bastantes la libertad y la constitución ${ }^{57}$.

\section{Conclusión: Fragueiro, su derrota y su prognosis}

Pertenece a la historia el fracaso de la política económica pergeñada por Fragueiro: el derrumbe del papel moneda de la Confederación precipitaría su alejamiento del Ministerio, y encaminaría a la Confederación en la senda de la política económica clásicamente liberal delineada por Alberdi en su Sistema Económico y Rentístico de la Confederación Argentina según su Constitución de 1853.

En definitiva, la secesión de Buenos Aires, con el correspondiente escamoteo de la base rentística y del aparato gubernativo más desarrollado, impactaría sobre los planes constitucionales de Fragueiro y Alberdi: ambos, por razones geográficas, históricas y técnicas, habían considerado a Buenos Aires la capital natural del Estado. La consiguiente unidad sin centro a que quedara reducida la Confederación derruiría los cimientos de sus respectivos planes. Para Fragueiro supondría casi inmediatamente la sustracción -en virtud de la larga historia de moneda fiduciaria provincial y de su desarrollado aparato aduanero- del pilar central en que debía reposar la Administración del Crédito Público según sus Cuestiones Argentinas de 1852. Para Alberdi, y a pesar de las gestiones diplomáticas que emprendiera para torcer este rumbo, la reforma exigida por Buenos Aires supone la destrucción de su plan constitucional ${ }^{58}$, que sólo vería salvado a partir de la federalización de Buenos Aires por el Gral. Roca ${ }^{59}$.

56 M. Fragueiro, Cuestiones Argentinas y Organización del Crédito, op. cit., pp. 291-292.

57 Ibidem, p. 290.

58 J. B. Alberdi, Escritos Póstumos, Tomo XIV, Buenos Aires, Imprenta Juan Bautista Alberdi, 1900, pp. 811-819, 827-840. Alberdi afirma, entre otras cosas, que "[e]n todas estas reformas hay un plan oculto, pero ciertísimo, de acabar con la institución del gobierno nacional. Se invoca para ello el ejemplo de la Constitución de Estados Unidos. Es un pretexto hipócrita, y los que se dicen unitarios de tradición, no pueden creer de buena fe que convenga a nuestras provincias el sistema de gobierno que va siendo la ruina de México, Centro América, Nueva Granada y Venezuela" (aquí p. 832).

59 J. B. Alberdi, La República Argentina consolidada en 1880 con la ciudad de Buenos Aires por capital, Buenos Aires, Imprenta de Pablo Coni, 1881. 
No es azaroso que, en retrospectiva, la legitimidad histórica del dispositivo constitucional surgiera de su apropiación política posterior. Sin embargo, desde el punto de vista de sus contemporáneos, su legitimidad abrevó en lo fundamental de su orientación futurocéntrica. En una visión algo pesimista respecto de los alcances efectivos de los proyectos de nación elaborados por los románticos argentinos, Halperín Donghi afirmó que, "Alberdi -con su proyecto de «progresismo autoritario»- había tenido razón: los cambios vividos en la Argentina son, más que el resultado de las sabias decisiones de sus gobernantes posrosistas, el del avance ciego y avasallador de un capitalismo que se apresta a dominar todo el planeta"60. Pero si la parsimonia argumental de Alberdi permite atribuirle esta vaga previsión, no menos verdaderos son los aciertos de Fragueiro - que Alberdi repudiara- en el plano de la prognosis. En efecto, la marcha del tiempo revelaría que los Estados modernos formarían instituciones de crédito público que, entre otras funciones, monopolizarían la emisión monetaria y regularían la circulación del crédito (nos referimos a los Bancos Centrales); más aún, a medida que avanzara el siglo XX su función se relacionaría cada vez más con la democratización del crédito hasta llegar a la actual financierización casi total de la vida social. El gran ciclo inmigratorio argentino que alcanzara su cenit entre fines del siglo XIX y principios del XX, por su parte, mostraría en sus tendencias demográficas generales el acierto de la previsión fragueriana respecto a su inclinación urbana, incentivada también por la oligarquización latifundista. En una medida no desdeñable, los festejos del Centenario de la Revolución de Mayo en 1910, bajo la declaración de "estado de sitio" y acompañados de leyes anti-inmigratorias con un claro sesgo de persecución ideológica, dan cuenta también de su acierto respecto a la inexorable emergencia vernácula de la denominada "cuestión social". Más cerca de nuestros días, y desde la finalización unilateral del pacto Bretton Woods, la globalización ha marchado de la mano de una fiduciarización dineraria a escala planetaria, inconcebible desde el metalismo monetario alberdiano. En definitiva, y a pesar de la centralidad histórica alberdiana, el largo aliento parece revelar un mayor acierto en la prognosis del derrotado Fragueiro. 
